\title{
Using Behavioral Economics to Analyze Credit Policies in the Banking Industry*
}

\author{
David Peón ${ }^{1}$, Anxo Calvo ${ }^{2}$
}

\begin{abstract}
:
2008 world financial meltdown highlighted significant shortcomings on procedures used by the banking sector to provide credit to the real economy. A long period of indulgence granting personal loans and mortgages that boosted a credit bubble all over the world has been followed by an era of suspicion within the banking sector, precipitating the liquidity crunch and the credit squeeze to private agents.

Behavioral Finance has emerged as an alternative approach to analyze efficiency on financial markets, revealing a world with less than fully rational investors and arbitrageurs limited by risk aversion, short time horizons and agency problems. In this paper we consider the possibility to extend Behavioral Finance topics such as investor sentiment, overconfidence, heuristics or herd instinct to analyze banks behavior when providing credit to private agents, and how the absence of arbitrageurs in the credit market could justify the role of public banking as a countercyclical policy maker.
\end{abstract}

Key Words: Credit bubbles, EMH, banking efficiency, behavioral finance, limits of arbitrage JEL Classification: D03, E32, G21

\footnotetext{
Acknowledgement: Authors gratefully acknowledge Enrico Maria Cervellati (Universitá di Bologna) for his helpful orientation in Behavioral Economics.

${ }^{1}$ Grupo BBVA and Departamento de Economía Financeira e Contabilidade, Universidade da Coruña, Campus Elviñas/n,15071 A Coruña.Email: david.peon@udc.es

${ }^{2}$ Departamento de Economía Financeira e Contabilidade, Universidade da Coruña, Campus Elviña s/n, 15071 A Coruña.Email: anxo.calvo@udc.es
} 


\section{Introduction}

Are private banks efficient when providing credit to the real economy? Probably, in the last decades there has not been such a bitter debate in academic research as the one related to efficiency in financial markets. Hence, we will not find a unanimous answer to that question, but in the midst of the worst financial crisis since the Great Depression, it seems unavoidable to wonder how did all go wrong?

Kindleberger (1978) provided what Shleifer (2000) named the 'anatomy of a price bubble': a process that starts with some good news that generate a profit in an asset, followed by a 'smart-money response' where both the supply and the demand of such asset are encouraged by initial investors. The bubble is then sustained by the same investors, who “(...) stimulate positive feedback trading by (...) facilitating noise trader speculation" (Shleifer, 2000, p.172). That is, the same agents who are benefited in the early stages of the bubble generate a greater supply of the asset and encourage other actors to participate, increasing the demand and sustaining asset prices until the market, eventually, collapses.

Hens and Bachmann (2008) explain the anatomy of the financial bubble that led to our present crisis. They interpret the initial good news that rose prices on the real estate market as the speculative money coming into the house market after the dot-com bubble burst. Then, smart-money investors started the "packaging of mortgage risks in new securities (MBS) that are sold outsourced in special investment vehicles (SIV) and sold worldwide" (p.94).

This approach is focused on the role that subprime mortgages had in the process that led to the crisis, but in this paper we want to delve a little deeper into the study of how the 'smart-money response' promoted the credit growth in order to sustain the bubble. The financial meltdown highlighted significant shortcomings on procedures used by the banking sector when providing credit to the real economy for two reasons. First, a long period of indulgence granting personal loans and mortgages boosted the credit bubble all over the world, and second, after the collapse of Lehman Brothers, an era of suspicion within the banking sector precipitated the liquidity crunch and the credit squeeze to private agents.

A traditional approach to analyze market efficiency is the efficient market hypothesis (EMH) by Fama (1970) applied to capital markets. In this paper we will first provide a brief outlook on several ideas that behavioral economics has presented when analyzing the EMH in the context of capital markets, and then, in the bulk of this paper, we shall apply that analysis to the study of retail banking sector -both from a macro and a micro perspective- when granting credit to businesses and households.

\section{Behavioral Finance and the EMH on Capital Markets}

The efficient market hypothesis (EMH) postulates market prices reflect the 'true value' of capital stock, given information available. Fama (1970) sees three 
categories in the EMH. Under the weak-form EMH, current stock prices fully reflect all currently available market information. Hence, past price and volume information would have no relationship with the future direction of security prices. The semistrong-form EMH assumes current stock prices adjust rapidly to the release of any market and non-market information available to the agents. Finally, the strong-form EMH version implies that prices fully reflect all public and private information. The strong-form assumes perfect markets where information is costfree and available to all market participants at the same time. ${ }^{3}$

Empirical data has challenged the EMH. Relevant examples are Shiller (1981), De Bondt and Thaler (1985), Jegadeesh and Titman (1993), Siegel (1998) or even Fama (1991) and Fama and French (1992), which evidence market anomalies inconsistent with market rationality. Empirical evidence against the weak form EMH include stock market volatility much higher than justified by the expected net present value of future dividends, extreme losers (the worst performing stocks over a long period in the past) outperforming extreme winners in the short future -a sign of overreaction and return to the mean- or, on the contrary, for short term periods price movements over six to twelve months tend to predict future movements in the same direction (which is called 'momentum').

Evidence against the semi-strong form EMH are smallcap stocks earning higher returns than 'blue chips', or in market evidence that 'value investing' (buying the cheapest stocks in terms of market to book ratios) has historically outperformed 'growth investing'. Finally, there is also evidence against the strong form EMH, particularly when markets move sharply without any apparent news (as in several market crashes and other large one day stock price movements), or when the inclusion of a stock into a market index provokes a substantial buying of shares when, matter of fact, that is unlikely to convey any information about the stock.

Behavioral finance could be defined as "the study of how psychology affects finance" (Shefrin, 2002, preface ix). Shleifer (2000) conducts an analysis of the efficiency of capital markets under a behavioral framing. He points out the EMH is supported by three arguments which rely on progressively weaker assumptions: "First, investors are assumed to be rational and hence to value securities rationally. Second, to the extent that some investors are not rational, their trades are random and therefore cancel each other out without affecting prices. Third, to the extent that investors are irrational in similar ways, they are met in the market by rational arbitrageurs who eliminate their influence on prices" (p.2).

The logic of the analysis is as follows. First, several psychological topics are used to analyze how agents select and process information from the market, which are their attitudes toward risk, and whether they have sensitivity to the way market information is presented to them. Through this analysis we determine whether all (or at least most) market participants do behave rationally or not.

\footnotetext{
${ }^{3}$ See Antelo and Peón (2012) for further interpretation.
} 
If there is evidence of agents being affected by cognition and emotional biases, this would not necessarily mean markets are not efficient. The EMH considers that if some investors are not rational, their biases will be random and hence they will trade against each other without affecting prices. Hence, behavioral analysis must determine whether irrational investors trade randomly or not.

Finally, if it is found that investors are irrational in similar ways, following some naive trends or in a correlated manner, there is a latter chance for EMH to hold. If there are rational arbitrageurs able to effectively make riskless profit from prices being out of their fundamental values, they will preserve efficiency on the market and the EMH will ultimately hold.

\subsection{Investor rationality}

Shleifer mentions three broad areas where people deviate from rationality attitudes toward risk, non-Bayesian expectation formation and sensitivity to the framing of problems. However, we find more clear the approach that Shefrin (2002) used to determine that "(...) a few psychological phenomena pervade the entire landscape of finance" (Shefrin, 2002, p.4). He distinguishes two main sources of psychological biases: heuristics (the process through which people try to find out relevant information from all news and market data) and framing biases (the fact that how a problem is presented -and not the data itself- could lead market participants taking irrational decisions).

We complete this classification with that provided by Hens and Bachmann (2008), who classify behavioral biases as those that are committed when selecting information, when processing that data, and when deciding, where framing is just one of the biases in the second group. The idea behind all of these terms is that people filter information through proxies (called heuristics or 'rules of thumb'), since market data is vast and changes every second, and that filtering process may be affected by cognitive or emotional biases. We will just mention some of them, since we later discuss in detail those that are relevant to our analysis.

Heuristic biases: availability heuristic (tendency to pay attention to pieces of information that are easier to get or understand), representativeness (reliance on stereotypes) and gambler's fallacy (tendency to see patterns in truly random sequences), overconfidence (and related concepts as illusion of control and longshot bias), anchoring (being influenced by arbitrary -even non informative- data) and conservatism (tendency to underreact to news consistent with one's beliefs), aversion to ambiguity (ambiguity introduces fear to the unknown), etc.

Framing biases: loss aversion (first mentioned by Kahneman and Tversky, 1979), mental accounting (problems analyzed in an isolated fashion), disposition effect (a consequence of loss aversion combined with mental accounting), house money effect (also a consequence from mental accounting), money illusion (paying attention to nominal values disregarding the effects of inflation), home bias (preference for domestic stocks), self-control and regret (two emotional biases that may affect in the decision making process), etc. 


\subsection{Random irrationality}

The EMH is not invalidated by irrationality of investors since the second reasoning supporting market efficiency is that even when some investors are not rational, their trades may be random, so they do not affect prices.

If that is true, the strategies of the irrational investors should exhibit a lack of correlation. On the contrary, if we find some arguments supporting there is enough evidence that the cognition and emotional biases introduced in point 2.1 may result in a correlated behavior among irrational investors, then we might say there is odds for prices being driven out of their fundamental values. Shleifer claims that psychological evidence shows that people deviate from rationality mostly in the same direction. "This problem becomes more severe when the noise traders behave socially and follow each others' mistakes by listening to rumors or imitating their neighbors" (Shleifer, 2000, p.12).

This behavior affects not only 'common people', but also to professional investors, traders and dealers, pension and mutual fund managers, etc. Furthermore, not only professional managers are subject to the same behavioral biases as individual investors, but since they manage other people's money, their decisions could be severely affected by herd instinct. In capital markets and the asset management industry it is a frequent behavior to choose portfolios that resemble the benchmark the manager is evaluated against, or to make recommendations on stocks according to what other analysts or market consensus believe, in order to avoid a bad relative performance.

Herd instinct predicts, therefore, that due to imitation, following rumors, financial gurus and recommendations on media or many other biases that are shared among investors, irrational decisions are correlated and prices could potentially not fit their fundamental values.

\subsection{Limits of arbitrage}

Even if irrational investors behave in a correlated manner and prices are driven out of their fundamental values, the EMH argues that the existence of arbitrageurs in the market helps correcting mispricing eventually.

Here, our analysis of credit policies in retail banking will slightly differ from research on limits of arbitrage in capital markets. In capital markets there are indeed arbitrageurs that try to make a riskless profit in a market where correlated irrational investors drive prices out of their fundamental values. For that purpose, market participants having access to more complete sources of information, and through careful -and rational- research, look for mispriced stocks and try to correct them for their own profit. The central argument of behavioral economics is that, in real world, arbitrage is actually risky and limited, so even arbitrageurs -that are risk averse, have limited time period horizons and face agency problems- might not be able to ensure efficiency on markets.

On the contrary, our first question when analyzing how banks grant credit to private agents is who might play that role of arbitrageur inside the banking industry. 
After we identify who plays (or could play) that role, we will then analyze the limits of arbitrage in that field the same way Shleifer did for capital markets.

\section{Applying BF to a New Framework: Efficiency of Credit Policies on Retail Banking}

We are going to consider the possibility to extend Shleifer's analysis of capital markets efficiency to a new framework: credit policies on retail banking. We delimit retail banking as the transactions from banking institutions to their customers, and credit policies as the personal loans, mortgages, credit accounts, credit cards and other credit instruments that commercial banks provide.

We will also differentiate that the allocation of credit to the real economy takes place at two levels. First, from a macro perspective, managers decide the volume of resources that each bank is ready to grant in form of loans and mortgages, according to the cost of funding in the interbank market and the macro situation they perceive both for economic growth and expected demand for credit. Credit markets are likely more complex than markets of goods and services because price is not the only variable that counts to match supply and demand. Risk is the other feature that must be considered, so banks limit their bid for each level of interest rates, allocating credit among potential customers according to the creditworthiness perceived.

Second, from a micro perspective, the decision whether to extend credit or not to each particular agent that demands it is up to both employees at commercial branches and risk analysis departments. Usually credit levels that are considered to be suitable from a macro point of view are passed down in form of commercial goals. Then, commercial success is often used as feedback when re-evaluating macro expectations.

Our main purpose - since we will not present any statistical evidence or propose any mathematical model that would suit that data- will be posing an alternative approach to the study of efficiency in retail credit markets and leave some open questions for future research. We will follow a three step process like Shleifer: 1. do banks (managers and employees) behave 'rationally' when granting credit to the economy? 2. are irrational policies random? 3. how may arbitrageurs ensure the financial sector provides credit in an efficient manner?

\subsection{Analysis of rationality on credit policies of retail banking}

What does 'efficiency' on retail credit markets' mean? In financial markets, efficiency implies that a market is able to accurately assess all available information in order to provide an asset price that is equal to its fundamental value. Using that approach, what should we understand by efficiency in retail credit markets? What does it mean that credit institutions are rational when providing credit to the market?

The crucial role of agents in the credit market is to assess demand of credit, and with a potentially unlimited supply (under the fractional-reserve banking 
system, where most money in the economy is created by financial institutions, there are potentially no limits for the creation of new money other than the reserve requirements imposed by the Central Bank), decide which level of credit is supplied and who is given credit and who is not. Analyzing rationality of retail banking when providing credit to the economy entails evaluating whether people involved in the selection process have emotional or cognitive biases, and whether these biases could make the banking sector feed speculative bubbles in the economy or provoke a credit squeeze when there are actually agents in the market that could continue to be financed at low risk.

This debate about efficiency represents, therefore, a discussion on risk perception and prudence. Risk perception in the sense discussed above -financial institutions and supervisor authorities not entirely appreciating the risk of an eventual collapse in the real estate market, or probably overweighting risks when giving credit to creditworthy agents during economic recessions-, and prudence in the sense of determining, for a potentially unlimited supply, how much credit is given to the economy from a macro perspective, and which agents will receive credit and which not from a micro point of view.

Therefore, we may consider that banks consequently analyze the credit market in two dimensions: at a macro level, they would analyze the economy and look for patterns in economic growth, its sustainability and the future demand for credit; at a micro level, it would require evaluating several aspects for credit analysis such as the candidate's credit history, the ability to pay, capital available to respond for credit, the existence or not of collateral, etc. Under that approach, we will try to identify several cognitive and emotional biases as those inventoried in part 2.1 that could be reasonable observed in credit policies of retail banking both from a macro and a micro perspective.

Heuristics and framing biases that have been identified in financial markets would also be relevant in retail credit markets, since those are all emotional and cognitive biases that are common to everyone. Our concern here is to point out some of them that could have a greater effect over the amount of credit, the easiness and the rationality with which credit is granted to the economy. Obviously, having empirical evidence about it would require setting a quantitative study on this area.

Shleifer (2000), for example, bases his 'model of investor sentiment' in financial markets on two biases: conservatism and representativeness. ${ }^{4}$ In our opinion, conservatism could be determinant for our analysis from a macro perspective. Conservatism "states that individuals are slow to change their beliefs in the face of new evidence" (Shleifer, 2000, p 128) and it would explain, for example, the underreaction of bank managers and supervisor authorities to evidence of credit policies fostering real estate bubbles and their latter collapse. The influence of conservatism on the decision-making process by managers and supervisors would

\footnotetext{
4 "Our model is motivated by two important phenomena documented by psychologists: conservatism and the representativeness heuristic". Shleifer (2000, p.127).
} 
not be quite different from the effect that it has over investors on the stock market or professional fund managers.

Representativeness, on the other hand, could be relevant from a micro point of view. Shleifer (2000) provides an idea of what representativeness means through an example: if a description of a person matches with the subject's experiences with people of a particular profession, the subject tends to significantly overestimate the actual probability that the given person belongs to that profession. ${ }^{5}$ Applied to our framework in this paper, if an employee working at the branches of a retail bank has had good experiences giving credit, say, to several dentists, he might exhibit a tendency to consider suitable a new potential costumer only because she is a dentist. So when it comes to analyze her economic situation and creditworthiness, he could exhibit a bias to overweight good data and underestimate risks.

Hens et al. (2008) also relate representativeness to the phenomenon of 'gambler's fallacy' (that is, the tendency to see patterns in truly random sequences). Applied to our example above, an employee working either at the branches or at the risk analysis department of a financial institution could consider that a company that is exhibiting very good results and a high growth in recent years (for example, a builder or a developer during the real estate bubble) will be able to maintain or even improve that performance in the future.

Two other biases that could have a relevant effect over agents at a macro level are overconfidence and loss aversion (Shefrin, 2002). Overconfidence of bank managers and supervisor authorities would have a similar impact as it has in stock markets, for example, where some agents could be overestimating the accuracy of their predictions. In financial markets this would cause prices to overreact -" (...) if investors are overconfident, they may overestimate the precision of their private information, causing prices to overreact" (Hens and Bachmann, 2008, p.81)- the same way as in credit markets this could have led to a lower risk perception under a trending up real estate market. Hens and Bachmann (2008) also mention the possibility of those overconfident agents to exhibit in some cases an 'illusion of control'. That is, judging an outcome as a consequence of their acts when in fact they have been simply lucky “(...) even if they know that success or failure depends on chance. The greatest satisfaction, or a feeling of competence, is achieved from being able to control the seemingly uncontrollable" (p.81).

Whereas we could use overconfidence to analyze agents' behavior when credit markets boost, loss aversion could be used to explain what happened next. That is, during recessions and due to suspicion and lack of confidence within the financial sector, bank managers become more sensitive to avoid loses than to profit from low-risk credit operations. As Kahneman and Tversky (1979) proposed in Prospect Theory, variance of returns becomes not a satisfactory measure of risk when agents are more sensitive to avoid losses. "They find that a loss has about two and a half times the impact of a gain of the same magnitude" (Shefrin, 2002, p.24).

\footnotetext{
${ }^{5}$ Based on an example by Shleifer (2000, p.128)
} 
Finally, it seems reasonable that biases such as availability (paying attention to pieces of information that are easier to get or understand), mental accounting (tendency to analyze problems in an isolated fashion instead of altogether), 'money illusion' (disregarding the effects of inflation) or 'anchoring' (being influenced by arbitrary, even non informative, data), among others, could also have a noticeable effect on agents both on a macro and a micro perspective.

\subsection{Analysis of correlation}

We have seen there are several biases that justify why some agents may be boundedly rational. In fact, one may think that believing that every single agent in the market behaves strictly rational would be indeed too naive. Anyway, the fact that many agents in the market may not behave strictly rational is not such a challenge for the EMH, because what it matters is whether that irrational behavior is correlated amongst agents or not.

Could we expect agents in retail banking be irrational in a random fashion? That would imply that while some banks are understating risks, others may behave too prudently. That is, while the former would grant loans and mortgages to satisfy almost any sort of demand they face, the latter would impose stronger restrictions than rationally required. Otherwise, if that behavior is not random across agents in the market, then we might say there are odds for an inefficient credit market.

Our main objective here will be to suggest some biases that could justify retail banks could sometimes exhibit correlated credit policies. We identify two different interpretations, at a macro and at a micro level.

\subsubsection{Macro perspective: 'herd instinct'}

From a macro point of view, 'herd instinct' could justify correlation. For instance, with the 2007-2008 world financial meltdown we became aware that almost every financial institution all over the globe had been trading on subprime mortgage backed securities. Another example, the 'stress tests' by the Committee of European Banking Supervisors (CEBS, 2010) evidenced that about a $60 \%$ of the losses that the Spanish Savings Banks would experience under the worst scenario would come from real estate risks.

It is not just a matter of banks not being able to detect when they are understating risks, it is a matter that maybe they are aware of them, but not following the trend would leave them 'out of the game'. Following competitors' behavior reduces risk of underperformance. Furthermore, those banks that are not willing to 'play the game' (that would mean, for example, not increasing the level of credit provided to the market when all institutions are doing that) must be aware that their strategy would lead to a decline in their market share. It is quite tough for managers having to explain their shareholders why they are not making money when all the other banks in the market seem to be making it easily...

One recent example is Goldman Sachs, which was sued for betting against synthetic products designed by the investment bank itself and sold to their 
customers. That might be an evidence of some market participants being aware that risks on the market could be relevant, but still they are not willing to lose market share. Another example, after several law changes, Spanish Savings Banks faced a new scenario where they could compete against them all across Spanish market. In order to gain market share in venues away from their natural markets, many Savings Banks would probably had to take more risks during the housing boom, financing operations that local banks were not willing to finance. As this strategy would have been done by all entities willing to win market share out of their local markets, this would explain the results of the CEBS (2010) stress tests.

\subsubsection{Micro perspective: 'obedience to authority'}

From a micro point of view, Milgram's behavioral studies of 'obedience to authority' (Milgram 1963, 1974) could provide an interpretation. In his famous experiment, psychologist Stanley Milgram suggested that most people were able to perform acts that violate even their deepest moral beliefs: people in the experiment were required to give fake (but they were unaware of it) electro-shocks up to 450 volt to other participants in the experiment to the extent to cause them severe damages or even death. "I set up a simple experiment at Yale University to test how much pain an ordinary citizen would inflict on another person simply because he was ordered to by an experimental scientist" (Milgram, 1974). They were not compelled to do it under no coercive methods, only just asked to do it because it was supposed to be required for scientific purposes. He found out that relatively few people had the initiative needed to resist authority.

How could the results of the Milgram experiment explain a correlated behavior in the retail banking industry? Bank managers assess market fundamentals from a macro perspective and then transmit those levels down to their branches in form of commercial goals. Employees at commercial branches are not only required to evaluate potential demand for credit to determine whether a loan or mortgage should be granted, but they are also required to commit to those commercial goals.

Under this situation, it could happen that the decision-making process would be guided by feelings rather than by rational analysis. When an employee is set some commercial goals, it could become more important to achieve them than to carefully evaluate demand suitability. Meeting commercial goals involves a personal satisfaction of 'mission accomplished', whereas not fulfilling the targets could lead to disesteem or even to some kind of punishment. The more is needed to meet goals, probably the less strict analysis on the suitability of credit will be conducted ('greed and $f e a r^{66}$ ). This behavior based on emotional factors would have a greater impact when a competition among employees of the same entity is set, such that it could happen that some of them, in order to 'be first', focus mainly on selling more

\footnotetext{
6 "Beyond greed and fear" is the title of the book by Shefrin (2002), where greed and fear are claimed to be two of the most important sources of emotional biases.
} 
mortgages and loans than their colleagues rather than assessing risks. The rest of their colleagues will then try to follow them in order not to underperform.

Hence, a trend will be developed by the feedback effect of the commercial goals achieved: bank managers set commercial goals based on macro perspectives; employees fulfill those expectations by meeting commercial goals; and then managers evaluate again their objectives based on the belief that, since goals have been achieved, probably there is odds for more supply of credit, so new (higher) commercial goals are re-set, and the wheel keeps going on. Although it is true there is commonly a separation between business and risk analysis departments, we have on one hand that those departments are usually also set targets, and on the other hand, that frequently banks may allow -to some extent- the same people taking business decisions and evaluating risk analysis.

Finally, agents' bounded rationality may not only promote trends on credit policies, but also on the real economy. People on the market tend to trust market participants that are supposed to be better informed than average or having better resources and skills to assess the economic situation. When small investors see big companies making money in the real estate market, many of them would wonder whether to imitate them. So when they go to a bank to ask for credit and they see banks grant it without much problem, that reinforces their expectations. Thus, perhaps 'herd instinct' in the financial sector fuels not only inefficiency on credit markets, but also on the real economy, reinforcing overconfidence of market participants and causing further overreaction.

\subsection{The role of arbitrageurs}

Given market participants may sometimes be boundedly rational, and with the possibility that such behavior could be correlated across participants, there is yet one last chance for efficiency to hold in retail credit markets: finding rational arbitrageurs that are able to eliminate irrational behavior's influence.

What do we understand by arbitrage ${ }^{7}$ in retail credit markets? In financial markets, Shleifer (2000) analyzes whether there could be 'close substitutes' for a given security. An arbitrageur that sees an over demanded security -say, a telecom stock- could sell that stock and buy a close substitute for that company -that is, another telecom stock that could be considered a fundamentally identical asset- in order to try to benefit from the mispricing of the former security. In retail credit markets, instead, that arbitrage between 'close substitutes' would require that a bank, after observing a mortgage that has been granted underestimating creditor risks, could make a profit by granting a new mortgage to other costumer and 'shortselling' the former. That makes no sense. The risk assumed in every credit operation cannot be offset with the reduction of credit granted to any other agent in the market.

\footnotetext{
${ }^{7}$ Defined by Sharpe et al. (1990) as "the simultaneous purchase and sale of the same, or essentially similar, security in two different markets for advantageously different prices".
} 
Nonetheless, it might make sense to consider hedging at a macro level. That is, could we find agents in the market that will be able to rectify the excess credit provided by the banking system during credit bubbles -and the opposite when they fail to give credit- for their own profit? That role in our economies is played by Central Banks, but their function has been limited to basically setting the official set of interest rates and act as a lender of last resort for private banks. The effectiveness of Central Banks promoting stability and economic growth has been challenged several times, like nowadays. Under the fractional-reserve banking system, Central Banks do not have direct control over most of the money supply in the economy: during periods of economic growth, they can regulate the amount of credit granted to the economy through monetary policy tools -such as official interest rates, open market operations or reserve requirements ${ }^{8}$ - but during recessions their effectiveness is limited due to 'liquidity traps" and 'pushing on a string' ${ }^{10}$ situations.

Could we find private agents able to play that role of arbitrageur at a macro level? We try to answer this question while going through an analysis of which properties should such an arbitrageur meet. As stated by Shleifer (2000) for financial markets, the main limit to arbitrage is that irrational effects of behavioral biases over market conditions may become much worse before they disappear. A private arbitrageur on the retail credit market would be exposed to suffer losses if market inefficiencies continue for a long time or even amplifies before they disappear. Arbitrageurs would be limited by their time horizon and their risk-aversion in a 'real world' where arbitrage is actually risky.

During periods when banks are making money by giving credit to any potential buyer, with overconfidence reigning in an apparently unbeatable economic environment, an arbitrageur should be willing not to win that 'easy money', quit from granting more credits and lose market share even to the point of providing no credit at all. The opposite should be done when banks stop granting credits either because they are acting irrationally or because they are trapped in a prisoner's dilemma: an arbitrageur should be willing to give credit at a lower cost when the economic environment has worsen and probably the shareholders and the managers of such private entity acting as an arbitrageur would not be keen to do so.

\footnotetext{
${ }^{8}$ A measure almost obsolete because "it is quite tough for economic authorities to regulate the money supply through the reserve requirements, because a mandate to increase them can be followed by a decision of the private bank to reduce its (voluntary) excess reserves, offsetting their effects" (Antelo and Peón, 2012, p.30)

${ }^{9}$ A 'liquidity trap' is a situation in which Central Bank's monetary policies become ineffective. In Krugman words, "at an interest rate near zero the demand for money must become more or less infinitely elastic, implying that the leftmost parts of the LM curve must actually be flat. (...) Then changes in the money supply, which move LM back and forth, will have no effect on interest rates or output; monetary policy will be ineffective" (Krugman, 2000).

${ }^{10}$ A 'pushing on a string' situation is a concept related to 'liquidity traps'. It is a metaphor that suggests Central Banks' monetary policies are effective slowing economic growth (Central Banks may rise interest rates, so private banks are pulled to cut lending) but ineffective under severe recessions, because banks tend to accumulate excess reserves and Central Banks are unable to push them to lend.
} 
Since potential arbitrageurs would be commercial banks, they could also use their remuneration policy for deposits in order to arbitrage the credit market. During credit bubbles, an arbitrageur would need to raise the interest rate paid on deposits. This way, the other financial institutions in the market would be compelled to do the same, in order not to lose market share, so their cost of funding would raise and they will start imposing more stringent conditions on credit. Meanwhile, during recessions arbitrageurs should be careful with their policies on deposits. On one hand, they must pay enough to have funds sufficient to provide the credit required to the market, but on the other hand they must be aware not to tight the other banks' cost of funding in order not to worsen the financial environment.

Although in this paper we have not considered the influence of the interbank market, we might conclude arbitrage cannot be profitable: it would require paying for deposits more than required and not to be willing to earn 'easy money' during credit booms and the contrary during recessions. Hence, there is no incentive for private agents to do it and, even if they had the incentives, the resources needed would be enormous, because arbitrageurs should compensate the deviation that all the financial system would exhibit away from rationality.

Therefore, contrary to what happens in capital markets, where arbitrage can be executed by any well-informed, for-profit private agent in the market, it seems that arbitrage of retail credit markets could only be reserved, at most, to non-profit public entities. In our opinion, this could imply that efficiency of credit policies by the retail banking sector cannot be ensured, or at most, there would be a lower chance for this sector to be ultimately efficient -compared to capital marketsbecause there are no substitutes for arbitrage at a micro level, and at a macro level there would be no for-profit private agents willing to act as arbitrageurs.

\section{Concluding Remarks}

First, we have found very little research on this topic. Most behavioral economics research has been focused on analyzing efficiency of financial markets in general, and stock markets in particular, but paying little attention to retail credit markets and analyzing how agents behave when providing credit to the economy on the retail banking industry. Our analysis has tried to provide a first glance on that framework, and we believe it could be an interesting field to work in future.

Second, using behavioral finance to analyze retail credit markets requires a conceptual adjustment when talking about rationality and arbitrage mechanisms. Here, our analysis of retail banking rationality when providing credit to the economy should be focused to determine whether people involved in the selection process have emotional or cognitive biases, and whether these biases could make the banking sector feed speculative bubbles in the economy or provoke a credit squeeze. The analysis of arbitrage must be aware of the specific nature of these markets, but 
we neither appreciate the logics of arbitrage at a micro level, nor the possibility for private agents to arbitrage market conditions at a macro level.

Third, since it seems that arbitrage of retail credit markets could only be reserved to non-profit public entities, this would imply that efficiency of retail banking credit policies cannot be ensured -or at most, there would be a lower chance for this sector to be ultimately efficient, compared to capital marketsbecause there are no substitutes for arbitrage at a micro level, and at a macro level there would be no for-profit private agents willing to act as arbitrageurs.

Fourth, authorities must be aware of this specific nature of the banking industry. Regulation could play an essential role here. For example, we believe regulation should be strongly countercyclical to compensate 'herd instinct' and considering the perverse effects of manager incentives that could promote that behavior.

Fifth, authorities must be aware that 'herd instinct' in the industry is fed by banks as for-profit private institutions that could also have implications on agents' expectations in other markets in the economy. Therefore, regulators should promote features that ensure the role of banking as a public service. An alternative could be encouraging the existence of more non-profit organizations in the industry that could help soften 'herd instinct'.

Some lines of future investigation that we suggest could be implementing a quantitative analysis in order to find some empirical evidence of all ideas suggested here, and extending this model introducing the role of the interbank market and the effect of incentives. We could also analyze how herd instinct on retail credit markets could be avoided, which role regulation could play for that purpose, and whether regulation could enforce arbitrage.

Finally, another line of investigation may focus on the role of Central Banks and/or public banking to act as a market arbitrageur. However, it should be analyzed which policies a public bank should implement that truly fosters market efficiency while avoids potential political interferences. Furthermore, it also should be analyzed how this role of Central Banks and public banking would affect private banks behavior in a competitive market.

\section{References}

1. Antelo, M. and D. Peón (2012), Financial Markets: A Guided Tour, New York: Nova Science Publishers.

2. Committee of European Banking Supervisors CEBS (2010), 2010 EU wide stress testing, sited (28/07/2010) at www.c-ebs.org/EuWideStressTesting.aspx

3. De Bondt, W.F.M. and R. Thaler (1985), Does the stock market overreact? Journal of Finance, 40, 793-805.

4. Fama, E.F. (1970), Efficient capital markets: a review of theory and empirical work, Journal of Finance, 25 (2), 383-417.

5. Fama, E.F. (1991), Efficient capital markets: II, Journal of Finance, 46, 1575-617 
6. Fama E. F. and K.R. French (1992), The cross-section of expected stock returns, Journal of Finance, 47. 427-65.

7. Hens, T. and K. Bachmann (2008): Behavioral finance for private banking, John Wiley \& Sons Ltd.

8. Jegadeesh, N. and S. Titman (1993), Returns to buying winners and selling losers: implications for stock market efficiency, Journal of Finance, 48, 65-91.

9. Kahneman, D. and A. Tversky (1979), Prospect Theory: an analysis of decision under risk", Econometrica, 47 (2), 263-291.

10. Krugman, P. (2000), Thinking about the liquidity trap, Journal of the Japanese and International Economies, 14 (4), 221-237.

11. Milgram, S. (1963), Behavioral study of obedience, The Journal of Abnormal and Social Psychology, 67 (4), 371-378.

12. Milgram, S. (1974), Obedience to authority; an experimental view, Harpercollins.

13. Sharpe, W. and G. Alexander (1990), Investments, Englewood, NJ: Prentice Hall.

14. Shefrin, H. (2002), Beyond greed and fear. Understanding behavioral finance and the psychology of investing, Oxford University Press.

15. Shiller, R. (1981), Do stock prices move too much to be justified by subsequent changes in dividends, American Economic Review, 71, 421-36.

16. Shleifer, A. (2000), Inefficient markets. An introduction to behavioral finance, Oxford University Press.

17. Siegel, J. (1998), Stocks for the long run, New York: McGraw Hill. 
